\title{
Intemperismo simulado em animação gráfica
}

\author{
Maria Cristina Motta de Toledo \\ Professora Titular da Escola de Artes, Ciências e \\ Humanidades da Universidade de São Paulo - EACH/USP \\ mcristol@usp.br \\ Carolina Harumi Takayama \\ Graduada em Licenciatura em Ciências da Natureza da \\ Escola de Artes, Ciências e Humanidades da Universidade de \\ São Paulo - EACH/USP \\ carolina.takayama@usp.br \\ Christine Laure Marie Bourotte \\ Professora Doutora da Escola de Artes, Ciências e \\ Humanidades da Universidade de São Paulo - EACH/USP \\ chrisbourotte@usp.br
}

\begin{abstract}
WEATHERING SIMULATED IN GRAPHIC ANIMATION. Models, simulations and animations are very useful to help natural phenomena understanding, mainly geological processes, whose time scales are not compatible with human life scale. For weathering, which modifications occur below the surface, a new difficulty appears to observe the process. In this work, it has been produced a graphic animation about weathering, for use during different Geology teaching and diffusion situations. Moreover, it has been produced an auxiliary text and a guide for utilization. The whole tool was applied in some real situations (schools, teacher's meetings and scientific congress) and it has been positively evaluated by the public. Different softwares were used for developing the tool, which can be improved and enlarged, according to circumstances. Citation Toledo M.C.M.de, Takayama C.H., Bourotte C.L.M. 2014. Intemperismo simulado em animação gráfica. Terræ Didatica, 10(3):351-356. http://www.ige.unicamp.br/terraedidatica/.
\end{abstract}

KEYWORDS: Geology teaching, weathering teaching, didatic tool, graphic animation.

RESUMO A utilização de modelos, simulações e animações é muito útil para auxiliar na compreensão de fenômenos naturais, principalmente processos geológicos em escala de tempo incompativel com a escala possivel de ser observada pelo ser humano. No caso do intemperismo, em que as modificações naturais se processam abaixo da superfície, uma nova dificuldade se apresenta para a observação do processo. Neste trabalho, foi produzida uma animação gráfica sobre intemperismo para utilização em várias situações de ensino e de divulgação de Geologia. Além disso, foi também produzido um material explicativo na forma de texto auxiliar, bem como um guia de utilização do conjunto. O material foi aplicado em algumas situações reais (escolas, encontros de professores e licenciandos e oficinas em congresso de Geologia), tendo sido positivamente avaliado. O recurso utilizou vários programas e pode ser ampliado e aperfeiçoado, conforme a necessidade de utilização.

PALAVRAS-CHAVES: Ensino de Geologia, ensino de intemperismo, recurso didático, animação gráfica. 


\section{Introdução e Objetivo}

Um dos resultados da influência tecnológica na educação é, sem dúvida, o uso do computador em situações de ensino escolar ou mesmo fora das escolas. O uso da informática tem gerado discussões sobre a forma de aprender, de ensinar e do acesso às informações, bem como das novas posturas a serem usadas diante da tecnologia (Prado 2004). Segundo o mesmo autor, o acesso à Internet, assim como qualquer outra tecnologia, não pode assegurar por si só melhorias na qualidade do ensino, que depende de vários fatores; muitas informações estão disponíveis e, ao mesmo tempo, há uma preocupação que cresce acerca desses conteúdos. Assim, alguns recursos computacionais aplicados à educação não alcançam a solução dos problemas educacionais atuais; entretanto, eles podem contribuir para a melhoria da qualidade do ensino.

Como este, muitos trabalhos já discutiram aspectos variados sobre esta utilização, destacando vantagens, desvantagens e, sobretudo, cuidados que devem ser tomados para que esta utilização seja bem sucedida do ponto de vista pedagógico e não traga quaisquer problemas quanto a outros aspectos da vivência escolar, como a socialização, entre outros.

No caso do ensino de temas ligados à Geologia, tal utilização é particularmente interessante, pois pode permitir acesso a visualizações impossíveis do ponto de vista das escalas temporais e espaciais das feições resultantes dos processos dinâmicos terrestres. No entanto, segundo Barbosa (2003), o uso do computador não pode ser comparado a experiências adquiridas em atividades práticas, como saídas de campo, mas pode auxiliar com conhecimentos prévios, reconhecimento de feições e fenômenos da natureza, organização de dados coletados em campo e principalmente acesso de locais remotos quando não é possível a ida a esses locais. Mais recentemente, como no caso do presente trabalho, pôde-se aproveitar suas potencialidades em animações e simulações, contribuindo para a eficiência da visualização e compreensão de fenômenos geológicos.

Assim, este trabalho teve o objetivo de elaborar um recurso didático de animação gráfica, utilizando diferentes programas, do processo de intemperismo, incluindo o aprofundamento de um perfil intempérico e o detalhamento de alguns dos mecanismos importantes no processo, tanto de intemperismo físico como químico, a influência da biosfera e a formação de minerais supérgenos a partir de minerais comuns de uma rocha comum, o granito. A intenção é que o recurso seja utilizado em diferentes instâncias de educação e divulgação científica.

O material produzido é composto por arquivos graváveis e tanto pode ser acessado por meio de um CD-ROM, DVD ou qualquer outro meio local, como também via Internet, utilizando um servidor. Além das animações gráficas, há fotografias e explicações sobre os processos, para que o material contribua para a compreensão teórica, além da visualização dos processos nas animações, e um guia de utilização para os usuários.

A parte apresentada neste trabalho refere-se ao Intemperismo, mas foram desenvolvidas animações referentes também aos processos de formação de depósitos de areia, abordando a erosão, transporte e sedimentação dos materiais formados por intemperismo, e à apresentação de diferentes depósitos de areias em praias de todo o mundo; ambas foram apresentadas em outro trabalho (Bourotte et al. 2014).

O programa Flash ${ }^{\circledR}$ foi utilizado para grande parte do trabalho, como ferramenta que dá movimento às imagens elaboradas; no entanto, devido ao limitado espaço para texto, foi também utilizado o programa computacional Muse, para tornar as animações separadas dos conteúdos escritos, criando arquivo em HTML (Hyper Text Markup Language). Foi utilizada uma mesa digitalizadora da marca Wacom Tablet Bamboo do modelo Pen e Touch para facilitar as artes gráficas no programa Flash, a fim de aumentar o rendimento no tempo de execução. Por fim, outras ferramentas computacionais foram utilizadas: Adobe Illustrator, compatível com o Flash e com o Muse, e Adobe Dreamweaver.

\section{A utilização de animações no ensino de Geologia}

No caso das Ciências da Terra, em que os objetos de estudo variam não apenas em dimensões (do infinitamente pequeno - átomos - ao imensamente grande - continentes, oceanos, Sistema Solar), mas também em duração de ocorrência ou existência (processos muito rápidos, que não permitem o acompanhamento das etapas, ou processos tão lentos que não são percebidos na escala da vida humana), os recursos computacionais para simulações e animações podem ser poderosas ferramentas de aprendizagem.

A ideia de que o uso da imagem em Geologia é 
particularmente útil é fundamental neste trabalho. Segundo Compiani (2002), a linguagem escrita não é suficiente para dar conta da complexidade das representações das explicações em Geociências; os aspectos verbal e visual devem estar juntos para maior eficiência das explicações. Assim, a função das imagens é muito mais ampla e significativa do que apenas auxiliar na transmissão baseada na comunicação textual e verbal, conforme discutido por Amador (1998, apud Barbosa 2003), cabendo, então, à imagem um papel de grande importância, com destaque para o desenho, no contexto dos programas computacionais para ensino ou demonstração na área das Ciências Naturais.

Considera-se que uma adequada representação gráfica pode substituir páginas de texto, tornando-se parte vívida e memorável da informação, de acordo com Briscoe (1990), que afirma, ainda, que, além de fornecer uma descrição sucinta, o desenho acrescenta vigor à apresentação oral ou escrita. O mesmo autor considera, ainda, o desenho mais apropriado que a fotografia para a divulgação do conhecimento, enumerando algumas de suas vantagens, dentre elas: simplificar a representação de partes complexas; sintetizar em uma única imagem elementos presentes em diferentes fotografias; enfatizar detalhes na imagem; isolar aspectos essenciais; eliminar aspectos que podem distrair o observador; demonstrar a série de operações empregadas na realização de uma experiência.

O uso do computador permite, também, o avanço nas representações dos modelos da ciência, possibilitando que os processos deixem de ser descritos para serem simulados, favorecendo ao aluno o controle de parâmetros e das variáveis em estudo (Signoretti 2009). Segundo Medeiros (2002), as simulações podem ser utilizadas para representações ou modelagens de objetos específicos imaginários ou reais, de sistemas ou fenômenos, sendo bastante úteis, principalmente quando a experiência real for impossível de ser reproduzida pelos estudantes, o que é comum para os fenômenos naturais, entre eles os geológicos, lembrando que, segundo Lucena Junior (2005), para que seja atingido um objetivo estético, o animador deverá controlar todos os detalhes da animação e, nas simulações do universo real, deve-se seguir suas regras, pois qualquer interferência em fenômenos e comportamentos deixaria de ser uma simulação verdadeira.

É justamente nesta questão da transformação de imagens estáticas em processos contínuos que reside a importância do trabalho apresentado neste texto que, pela primeira vez no Brasil, elabora e divulga uma animação didática de processos da dinâmica externa da Terra.

\section{0 recurso elaborado: intemperismo em animações}

Será aqui apresentado um resumo do recurso didático elaborado, com algumas figuras representando, estaticamente, os processos animados, e com parte dos textos explicativos, elaborados conforme conceitos de Toledo et al. (2009), para contextualizar as figuras extraídas das animações elaboradas.

Intemperismo: As rochas que estão na porção externa e superficial da crosta terrestre estão sujeitas a condições que alteram as suas características físicas e químicas, buscando o equilíbrio com estas condições superficiais, diferentes das condições de formação das rochas duras, quaisquer que sejam elas (ígneas, metamórficas, ou mesmo sedimentares). O conjunto destas modificações se chama intemperismo, que inclui a desagregação e a decomposição da rocha inicial, gerando um material diferente, inconsolidado, e que pode sofrer erosão posterior, passando em seguida ao transporte e sedimentação em locais mais baixos. O processo de intemperismo é também chamado de alteração superficial, alteração intempérica ou meteorização. Este texto é ilustrado por um perfil de intemperismo, representando uma das formações superficiais mais comuns da superfície dos continentes.

Intemperismo físico: Causa a fragmentação das rochas, por meio da desagregação e fraturamento de grãos minerais da rocha; assim, o material antes coeso torna-se friável e descontínuo. $\mathrm{O}$ intemperismo físico não promove modificações químicas. Alguns mecanismos de intemperismo físico são a fragmentação por gelo e por raízes, descritos a seguir.

Fragmentação por gelo: Temperaturas abaixo de $0^{\circ} \mathrm{C}$ promovem o congelamento da água presente em orifícios, poros e pequenas fraturas ocasionando, assim, a desintegração pela pressão exercida, já que a água aumenta de volume ao congelar, forçando as paredes da rocha ainda coesa. A figura 1 mostra o início da animação deste mecanismo de intemperismo físico, e, ao clicar em Avançar, a chuva transforma-se em neve, representando a queda de temperatura, a água infiltrada 




Figura 1. Parte inicial da animação da fragmentação por gelo

na fissura da rocha transforma-se em gelo que, por pressionar as paredes, fragmenta o bloco de rocha.

Fragmentação por raízes: As raízes, com seu crescimento, também forçam as rochas nas quais penetraram, causando fissuras e desagregando-as. A animação desta parte mostra um pássaro voando e deixando suas fezes num bloco de rocha; sementes ali contidas acabam por germinar, uma planta cresce e suas raízes pressionam as paredes da rocha, fragmentando-a.

A fragmentação das rochas causa aumento da área superficial do material: Imagine um cubo com arestas de $8 \mathrm{~cm}$. Este cubo tem uma área superficial de $8 \mathrm{~cm} \times 8 \mathrm{~cm} \times 6$ faces $=384 \mathrm{~cm}^{2}$, para um volume correspondente de $8 \mathrm{~cm} \mathrm{x} 8 \mathrm{~cm} \times 8 \mathrm{~cm}$ $=512 \mathrm{~cm}^{3}$. Se o cubo for dividido por três planos ortogonais, nas três direções do espaço, formando 8 cubos menores, podemos recalcular a área superficial que pode ser atingida pela água, percebendo que ela é muito maior, já que o volume continua o mesmo e cada um dos cubos menores tem seis lados de $4 \mathrm{~cm} \mathrm{x} 4 \mathrm{~cm}$.

Neste caso, a área superficial de cada cubo menor é $4 \mathrm{~cm} \times 4 \mathrm{~cm} \times 6$ faces $=96 \mathrm{~cm}^{2}$. Considerando os seis cubos menores, a área superficial total exposta de $96 \mathrm{~cm}^{2} \times 8$ cubos $=768 \mathrm{~cm}^{2}$, muito maior, portanto, que os $512 \mathrm{~cm}^{3}$ iniciais do cubo não fragmentado. Isso significa que a rocha fragmentada tem mais superfície exposta para os agentes de intemperismo químico (basicamente, a água) agirem.

A animação desta parte mostra um bloco de granito sendo fragmentado e multiplicando sua área superficial para contato com os agentes de intemperismo.

Intemperismo químico: Promove a decomposição dos minerais primários por meio de reações químicas cujo agente principal é a água carregada em reagentes, resultando em minerais secundários (produzidos pela combinação de íons em solução) e solução de lixiviação (que transporta para fora daquele ambiente os produtos dissolvidos). As reações químicas do intemperismo promovem desestruturação do arcabouço cristalino do mineral primário, o que permite a liberação de íons em solução, os quais têm dois destinos: ou permanecem em solução, rodeados por moléculas de água, e são mobilizados no movimento da água subterrânea, ou combinam-se em novas estruturas minerais (minerais supérgenos, ou seja, gerados em superfície) que se precipitam no próprio ambiente em que ocorreu o intemperismo.

Para ilustrar o intemperismo químico, é mostrada a dissolução de um mineral, no caso, um grão de feldspato potássico (Fig. 2). Na animação, aparece água parcialmente ionizada (ou seja, com algumas de suas moléculas de $\mathrm{H}_{2} \mathrm{O}$ dissociadas em $\mathrm{H}^{+}$e $\mathrm{OH}^{-}$); os íons $\mathrm{H}^{+}$deslocam os cátions (no caso, $\mathrm{K}^{+}$), tiram a estabilidade da estrutura e assim a estrutura cristalina é destruída; ao ser deslocado para a solução, o íon $\mathrm{K}^{+}$é rodeado por moléculas de água, que se organizam segundo a atração elétrica por seu caráter de substância polar.

(Observação: a fórmula estrutural do feldspato potássico é $\mathrm{KAlSi}_{3} \mathrm{O}_{8}$. Um em cada quatro tetraedros não tem $\mathrm{Si}^{4+}$ como elemento central, mas $\operatorname{sim} \mathrm{Al}^{3+}$, e isso não está representado no desenho da animação; é a presença de $\mathrm{Al}^{3+}$ que causa um déficit de carga e permite a acomodação de $\mathrm{K}^{+}$, que neutraliza eletricamente a estrutura).

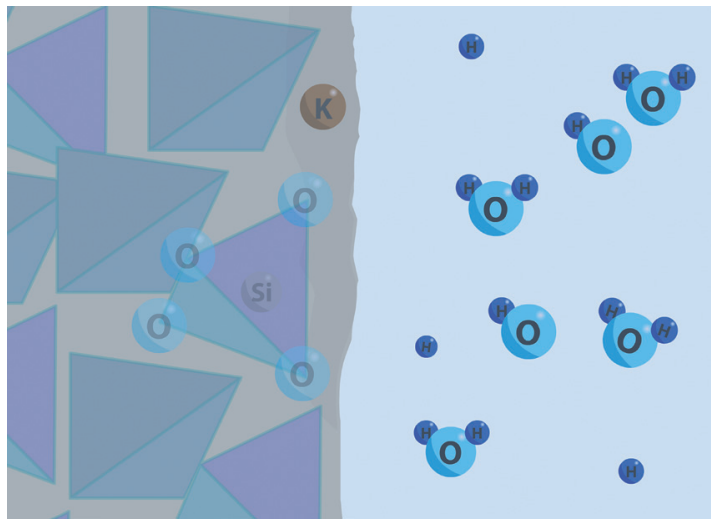

Figura 2. Imagem do início da animação da reação de dissolução, que mostra um íon $\mathrm{H}^{+}$substituindo o íon $\mathrm{K}^{+}$, deslocado e depois rodeado por moléculas de $\mathrm{H}_{2} \mathrm{O}$, seguindo sua polaridade elétrica 


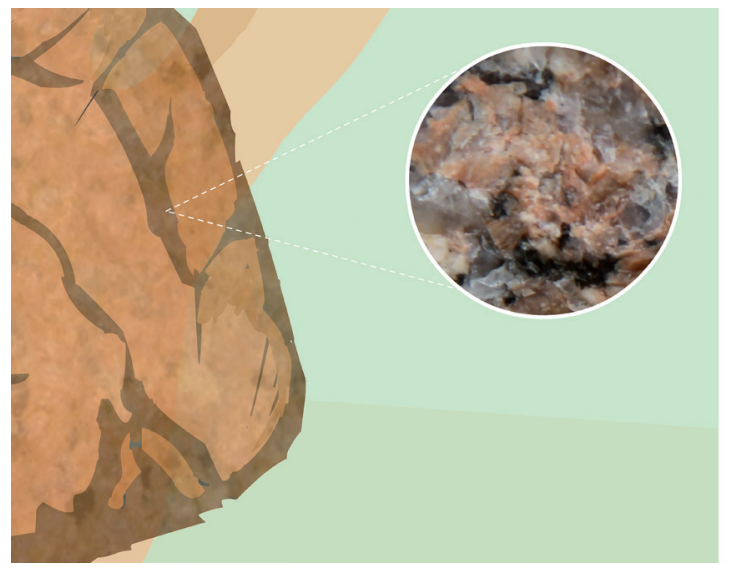

Figura 3. Início da animação do intemperismo químico e seus produtos

Produtos do intemperismo químico: $\mathrm{O}$ granito, rocha muito comum nos continentes, é constituído principalmente pelos minerais quartzo, biotita e feldspato; os produtos do intemperismo químico deste conjunto são: quartzo pouco alterado (pois é um mineral bastante resistente ao intemperismo químico), além de feldspato e biotita intemperizados, gerando íons em solução e novos minerais (minerais supérgenos: oxihidróxidos de ferro e de alumínio e argilominerais). Na animação, os minerais primários quartzo, feldspato e mica são destacados da rocha (Fig. 3), mostrando que cada um forma um produto secundário diferente, que depende não apenas das condições ambientais, mas também da sua composição química inicial.

Os materiais que formam os perfis de intemperismo contêm grãos minerais de vários tamanhos, predominando as três frações granulométricas mais finas: areia (de $2 \mathrm{~mm}$ a $0,062 \mathrm{~mm}$ ), silte (de $0,062 \mathrm{a}$ $0,002 \mathrm{~mm}$ ) e argila (grãos menores que $0,002 \mathrm{~mm}$ ); grãos maiores que $2 \mathrm{~mm}$ são, geralmente, fragmentos de rocha ainda não atingidos pelo intemperismo químico; esse material forma o que normalmente se vê na superfície do terreno, e que popularmente é chamado de "terra". Com o passar do tempo, o intemperismo aprofunda-se, pois os processos físicos e químicos atingem progressivamente partes cada vez mais profundas no perfil, de modo que o manto de intemperismo torna-se mais espesso com o tempo. Este aprofundamento do perfil pode ser heterogêneo, restando volumes sãos ou pouco alterados dentro do material intemperizado; este material, por sua vez, passa por erosão, que é seletiva, já que materiais maiores ou mais densos precisam de mais energia para serem mobilizados, ao contrário de grãos menores ou de minerais menos densos. Na animação do aprofundamento do perfil (Fig. 4), a superfície que separa a rocha sã da rocha alterada que vai se deslocando para baixo, irregularmente, como ocorre na realidade, deixando blocos semi alterados, que também evoluem na alteração, até chegar a uma situação de perfil relativamente aprofundado e contendo materiais em diferentes estágios de alteração.

\section{Aplicação do recurso para o público escolar e não escolar}

O trabalho foi apresentado em quatro eventos em 2012: a) I Congresso Internacional de Geociências na Comunidade dos Países de Língua Portuguesa (GeoCPLP2012), Coimbra, Portugal), b) $20^{\circ}$ Simpósio Internacional de Iniciação Científica da USP (SIICUSP, São Paulo), c) $46^{\circ}$ Congresso Brasileiro de Geologia (Santos SP), dentro das atividades oficiais de divulgação científica na denominada "Tenda de Geociências", dentro da Oficina de Areias, e d) na EACH-USP (São Paulo), no III Encontro de Estágios Obrigatórios e Experiências de Ensino, também dentro da Oficina de Areias, aplicada aos participantes interessados nesta nova experiência de ensino. No primeiro evento mencionado, em Coimbra, o público era formado por estudantes universitários e pesquisadores congressistas; o trabalho foi exposto na forma de painel, mas houve a possibilidade de apresentar a animação aos interessados, num computador colocado ao lado do painel. No $20^{\circ}$ SIICUSP, o público era formado basicamente por estudantes e professores da USP, e o trabalho foi exposto como painel, apenas. Em Santos, o público era composto por ampla variedade de pessoas, de várias idades, participan-



Figura 4. Imagens inicial e final da animação que mostra o aprofundamento do perfil de intemperismo 
tes ou não do Congresso em desenvolvimento, incluindo turistas em visita à praia onde a tenda foi montada; neste evento, a animação de intemperismo, por estar inserida na oficina sobre areias, foi mostrada no contexto da formação de depósitos de areias e do estudo das areias para determinação da história geológica dos locais onde se encontram. No último evento mencionado, na USP, o público foi composto basicamente por estudantes universitários e professores da rede pública de ensino, também no contexto de um estudo mais amplo, envolvendo o restante dos processos da dinâmica externa (erosão, transporte e sedimentação), com ênfase na formação de depósitos de areias, principalmente de praias. Finalmente, o recurso foi utilizado pelas professoras envolvidas no trabalho, em suas disciplinas de graduação na USP. Em todas as oportunidades de aplicação e apresentação do recurso o interesse demonstrado foi muito grande, tendo havido manifestações elogiosas e sugestões para ampliação do trabalho e das oportunidades de divulgação.

\section{Conclusões}

O desenvolvimento de ferramentas didáticas com suporte computacional mostrou-se, no exemplo trazido por este trabalho, como de grande utilidade para a apreensão de conceitos em Geologia e para a atração do interesse das pessoas que entram em contato com elas, quer sejam estudantes ou não. A iniciativa pode ser ampliada para maior detalhamento e inclusão de mais aspectos dos processos de intemperismo, bem como pode ser divulgada para que outros processos geológicos sejam transformados em animações na forma de produções que permitam não apenas o desenvolvimento acadêmico dos alunos que os elaboram, tanto em Geologia como em Informática, mas também que permitam a construção de um acervo nacional para uma das aplicações nobres da computação na sala de aula e em outros ambientes educacionais: o ensino e a divulgação da Geologia.

\section{Agradecimentos}

O trabalho foi desenvolvido graças ao apoio da FAPESP: (Processo 2010/19322-0) e CNPq, na forma de auxílios à pesquisa coordenados pelas professoras autoras deste trabalho, bem como na forma de bolsa à aluna de Iniciação Científica Carolina Harumi Takayama.

\section{Referências bibliográficas}

Barbosa R. 2003. Projeto Geo-Escola: Recursos computacionais de apoio ao ensino de Geociências nos níveis fundamental e médio. Campinas: Inst. Geoc. Unicamp. 131 p. (Dissert. Mestr.).

Briscoe M.H. 1990. A reseacher's guide to scientific and medical illustrations. New York: Springer. 209p.

Bourotte C., Toledo M.C.M.de, Duleba W., Aramaki G.T., Delissa L., Viana P.J. 2014. Kit didático "da rocha ao grão" .. de areia. Terræ Didatica, 10(3):298304. http://www.ige.unicamp.br/terraedidatica/

Compiani M. 2002. Geociências no ensino fundamental e a formação de professores: $\mathrm{O}$ papel dos trabalhos de campo. Campinas: Inst. Geoc. Unicamp. 99p. (Dissert. Mestr.).

Lucena Jr. A. 2005. Arte da animação: Técnica e estética através da história. São Paulo: Senac. 456p.

Medeiros A. 2002. Possibilidades e Limitações das Simulações Computacionais no Ensino da Física. Rev. Bras. de Ensino de Física, 24(2):80-81.

Prado A.S.do. 2004. O Uso da informática como ferramenta pedagógica no desenvolvimento de conteúdos de geociências no ensino fundamental. Campinas: Inst. Geoc. Unicamp. 87p. (Dissert. Mestr.).

Signoretti V.V. 2009. As Geociências na era da informação e a proposta curricular de Geografia no ensino fundamental em Minas Gerais. Campinas: Inst. Geoc. Unicamp. 124p. (Dissert. Mestr.).

Toledo M.C.M.de, Oliveira S.M.B.de, Melfi A.J. 2009. Da rocha ao Solo: Intemperismo e pedogênese. In: Teixeira W., Fairchild T.R., Toledo M.C.M. de, Taioli F. 2009. Decifrando a Terra. 2 ed. São Paulo: IBEP Ed. Nacional-Conrad. p. 210-239.

Waldhelm M.C.V. 2007. Como aprendeu ciências na educação básica quem hoje produz ciência? Rio de Janeiro: PUC/RJ. 224 p. (Tese Dout.). 